ARTIGOS

\title{
Algumas reflexões sobre as relações entre crianças, cidades e brinquedotecas
}

\section{Some reflections on the relationship between children, cities and toy libraries}

Dolores Galindo*

Docente da Universidade Federal do Mato Grosso - UFMT, Cuiabá, MT, Brasil

Leonardo Lemos de Souza**

Docente da Universidade Federal do Mato Grosso - UFMT, Rondonópolis, MT, Brasil

Morgana Moura***

Discente do curso de Psicologia da Universidade Federal do Mato Grosso - UFMT, Rondonópolis, MT, Brasil

Vanusa Rodrigues

Discente do curso de Psicologia da Universidade Federal do Mato Grosso - UFMT, Rondonópolis, MT, Brasil

\begin{abstract}
RESUMO
Este artigo tem como objetivo discutir as relações entre crianças, cidades e brinquedotecas. Para tal, foram analisadas três oficinas, realizadas como atividades de extensão, em uma brinquedoteca universitária situada num município de médio porte do interior de Mato Grosso. As oficinas foram gravadas em vídeo, transcritas e posteriormente analisadas tendo como unidades as cenas definidas em função dos movimentos da câmera ou finalização das brincadeiras registradas. Na análise, três aspectos chamaram a atenção: (1) a pluralidade de sentidos do termo cidade, (2) as articulações entre brinquedoteca e universidade que atualiza tensões existentes no plano macro das relações entre crianças e cidades e (3) as assimetrias na interação entre adultos e crianças durante as oficinas.
\end{abstract}

Palavras-chave: Infância, Crianças, Brinquedotecas, Cidades, Oficinas.

\section{ABSTRACT}

This article aims to discuss relations between children, cities and toy libraries. To this end, we analyzed three workshops, held as extension activities, in a toy university located in a midsize city of Mato Grosso. In the analysis of scenes, drew attention three aspects: (1) a plurality of meanings of the word city in the context of games, (2) the articulations and tensions between toy libraries and university and (3) the asymmetries in the interaction between adults and children during the workshops.

Keywords: Children, Child, Toy libraries, Cities, Workshops. 


\section{I ntrodução}

Nesse artigo, buscamos discutir a relação entre crianças, cidades e brinquedotecas, procurando refletir como, nestas últimas se fazem presentes tensões entre crianças e ordenações urbanas. Explora, basicamente, três eixos de indagação: 1) relações entre crianças e pesquisadores, 2) estratégias de apropriação do urbano por meio da multiplicidade de sentidos sobre a cidade e 3) relações entre brinquedotecas e universidades. Para tal, analisamos três oficinas realizadas, como atividades de extensão, em uma brinquedoteca universitária situada num município de médio porte do interior de Mato Grosso.

O presente trabalho se apóia em discussões que defendem a necessidade de rever a assimetria que caracteriza, historicamente, as pesquisas sobre a infância, valorizando o papel da criança na investigação (SOUZA, 1997; CASTRO, 2008). Desse modo, busca escapar aos modelos de investigação que concebem a criança pelo viés da abstração e do universalismo. Considerando esta perspectiva, ao longo da discussão, optamos por utilizar o termo "criança" no plural para enfatizar três premissas: 1) há uma ampla diversidade de possibilidades de infâncias; 2) a crítica ao essencialismo fundado na naturalização das idades da vida e 3) a infância e as demais categorias etárias são definidas reciprocamente. Quando mencionamos o termo infância, por sua vez, como categoria social, que é produzida e tem sentido no encontro e estranhamento entre gerações, ocupando uma posição relacional, isto é, dependente das demais categorias etárias.

Para organização do argumento, num primeiro momento abordamos a relação entre o cenário urbano e as crianças, em seguida, discutimos as pequenas subversões realizadas pelas crianças no espaço que geram fissuras na racionalidade urbanística. Passamos, então, à discussão das oficinas tendo em vista a discussão sobre as relações entre crianças, brinquedoteca e cidade e destas com os adultos durante as oficinas. A guisa de considerações finais, retomamos as implicações do que foi discutido para a problematização da brinquedoteca como mediadora das relações entre crianças, universidades e cidades.

\section{Cenário urbano e crianças}

Tradicionalmente, do ponto de vista do planejamento urbanístico marcado por uma racionalidade adultocêntrica, "a cidade é uma parte do universo na qual queremos iniciar a criança" (BROUGĖRE, 2004, p. 59), todavia, esquecemos que as crianças já estão, de maneira desigual, inseridas na cidade. No que diz respeito às práticas de organização do 
urbano, delineiam-se lugares construídos para crianças pautados pela inserção disciplinada dos infantes na cidade.

Historicamente, a criação das cidades coincidiu com a elaboração, normatização e privatização de espaços destinados à infância que, no Brasil, veio a ser intensificado nas primeiras décadas do século XX (ARIÉS, 1981; CORRÊA, 2006). Tais dinâmicas territoriais incorporam hierarquias de idade que limitam o acesso da criança aos dispositivos formais de deliberação acerca da vida em cidade. $\mathrm{Na}$ ótica do planejamento urbanístico, as crianças são posicionadas como sujeitos a serem protegidos, guardados, mas nunca consultados sobre os destinos da urbe (CRUZ, 2004). Antigos dispositivos como, por exemplo, a "roda dos expostos", adquirem o estatuto de práticas arcaicas a serem substituídas por programas direcionados à promoção do amor familiar (MARCÍLIO, 2006).

Todavia, a despeito dos projetos de inclusão controlada, no cotidiano das brincadeiras, as crianças subvertem a espacialização que orienta a lógica urbanística, delineando-se como sujeitos que reflexivamente, nos jogos e brincadeiras, participam da construção das cidades. Em outras palavras, as crianças crescem nas cidades e como sujeitos ativos constroem sentidos a partir das brincadeiras e brinquedos, dimensão que doravante nomearemos cidades pelas crianças

Nas brincadeiras são desenvolvidas estratégias de apropriação que, de modo complexo, fazem visível a tessitura heterogênea do urbano e, ao mesmo tempo, os modos contemporâneos de construção da infância. Apropriar-se do espaço urbano é condição para a vida cotidiana (BERTUOL, 2008; DEBORTOLI, 2008). Com isso, subterraneamente à cidade para as crianças (racionalidade do planejamento), enuncia-se uma cidade pelas crianças (racionalidade do cotidiano) as quais nem sempre convergem.

Bertuol (2008) argumenta que os lugares para criança são organizados em torno de uma lógica de controle assimétrica e que os pelas crianças, ao contrário, se dão de maneira informal pelo uso cotidiano. Semelhante argumento é também desenvolvido por Sarmento (2008) que diferencia culturas para crianças e pelas crianças. As primeiras são definidas como produções dirigidas, sobretudo, às crianças como consumidoras ou objetos de práticas de proteção e educação. As segundas, mesmo atravessadas pelas narrativas e dispositivos de controle sobre a infância, implicam em dinâmicas de singularidade, sendo materializadas, principalmente, na dimensão lúdica.

Ainda que a cidade para e pelas crianças nem sempre convirjam, estão imbricadas pelas hierarquias de idade e sentidos sobre a infância que perpassam a ambos. Na dimensão para predominam as relações de co- 
presença entre adultos e crianças e na segunda, ou na dimensão pelas, destacam-se as relações entre crianças (SARMENTO, 2005).

\subsection{Cidades para crianças: algumas políticas públicas}

A Convenção Internacional de Direitos da Criança, ratificada em 1989, pela Organização das Nações Unidas (ONU) estabeleceu novas bases para os direitos das crianças (CASTRO, 2001a). A partir daí, crianças passaram a ser posicionadas como "seres em desenvolvimento". A infância, assim como a adolescência, deixou de ser apenas um período de "moratória social", pelo menos, em tese, crianças adquirem, nas políticas públicas, o estatuto de cidadãs.

O sucesso da proposta teve como resultado a sua reedição, em 1994, pela UNESCO, sendo alçada ao estatuto de programa internacional que tinha como objetivo estimular o envolvimento das crianças, dos jovens e dos governos na avaliação e melhoria dos ambientes locais. A sua reedição, entretanto, levantou questionamentos relacionados à definição de seus objetivos, que não foram construídos com as crianças. Assim, as novas edições buscaram inserir de modo mais ativo a presença das crianças (BERTUOL, 2008).

Em conformidade com a Convenção, no Estatuto da Criança e do Adolescente (ECA), em vigor desde 1990 quando substituiu o Código de Menores de 1927 (que teve sua última alteração em 1978), a proteção integral da criança passou a ser uma responsabilidade distribuída entre Estado, família e comunidade (GOVERNO DO ESTADO DE SÂO PAULO, 1990).

O ECA é um marco na proposição do brincar como dispositivo de expressão, aprendizagem e promotor de habilidades e competências, parte essencial do direito ao lazer e à cultura. Com isso, desdobram-se, então, políticas públicas voltadas ao incremento de lugares destinados à infância vistos como condições para a efetivação de tais direitos.

À mesma época, algumas iniciativas voltadas à institucionalização da inclusão planejada das crianças na cidade, materializadas em programas e ações, se fazem presentes em iniciativas de planejamento urbano, das quais podemos destacar os programas Prefeito Amigo da Criança (1992), Município Amigo da Criança (1996) e Child Friendly City "Cidade amiga da criança" (1997).

Dentre essas iniciativas podemos citar Child Friendly City (Cidade "amiga da criança" - UNICEF, 1996) aprovada durante a segunda Conferência das Nações Unidas Sobre Assentamentos Humanos (Habitat II). Uma cidade amiga da criança é 
[...] uma cidade, ou qualquer sistema de governança local, empenhada em cumprir os direitos das crianças. É uma cidade onde as vozes, necessidades, prioridades e os direitos das crianças são uma parte integrante das políticas públicas, programas e decisões (UNICEF, 1996, tradução livre).

No Brasil, ganhou evidencia o programa Prefeito Amigo da Criança (1996), lançado pela fundação ABRINQ para os direitos das crianças, com o objetivo de comprometer os candidatos às eleições municipais com uma plataforma em favor das crianças e adolescentes. O prefeito que se inscreve no programa assume, por meio de implantação, implementação e fortalecimento de políticas públicas, programas e projetos nas áreas de Saúde, Educação, Proteção Especial e Orçamento Criança e Adolescente (OCA), o compromisso de priorizar a infância e adolescência em sua gestão, e faz isso com o auxílio do Guia Prefeito Amigo da Criança que orienta os participantes durante suas gestões (FUNDABRINQ, 2001)

Também com o intuito de promover a elaboração de políticas públicas dirigidas à criança como prioridade da administração municipal, a iniciativa Município Amigo da Criança (1996), com parceria da UNICEF, sensibiliza e estimula as autoridades municipais às políticas e práticas dirigidas à saúde da criança.

Do ponto de vista do planejamento das cidades, os locais informais das praticas subversivas entre crianças continuam sendo considerados perigosos. (GOMES; GOUVÊA, 2008). Delineia-se uma complexa geografia dos locais de circulação, sendo desenhadas zonas cujo acesso deve ser controlado pelo olhar adulto, inclusive, no que diz respeito ao contato com as culturas midiáticas e à internet que, como assinalam Salgado; Jobim; Souza (2007), integram a construção das infâncias no contemporâneo. Dessa maneira, programas sócio-educativos são, cada vez mais, oferecidos pelos equipamentos sociais de atendimento como alternativas às brincadeiras não controladas, ou seja, externas ao planejamento para crianças.

Não é fácil definir o que viria a ser uma efetiva inclusão das crianças, nem os dispositivos a serem utilizados para esta finalidade (CASTRO, 2001a). Tampouco são auto-evidentes as políticas dirigidas ao incentivo às brincadeiras que se oporiam ao trabalho infantil que, como demonstra Müller (2006), passa a ser integrado ao cotidiano escolar, cabendo a ele à formação dos pequenos trabalhadores. Não mais as imagens da carvoaria e rotinas extenuantes, mas da criança que tem, inclusive, no brincar uma das atividades conferidas e avaliadas no conjunto dos "trabalhos", ou atividades infantis. 
Deve-se alertar que o brincar, em si mesmo, não representa uma estratégia de resistência, ao contrário, pode integrar dispositivos disciplinares, de normalização e controle (LEMOS, 2007; 2008). As estratégias que envolvem a elaboração de políticas públicas para as crianças trouxeram contribuições significativas, principalmente, para as organizações municipais. Mas, não lograram a inserção das crianças como sujeitos ativos, pois, concentraram-se em solicitar que essas repetissem os modelos adultos hegemônicos, com exclusão, das brincadeiras que se dão nos espaços informais e não planejados (LYNCH, 1977; NIEUWENHUYS, 2003 apud BERTUOL, 2008).

\subsection{Cidades pelas crianças: transformações e subversões}

Mesmo com as restrições de circulação na cidade e com a falta de consenso sobre o que viria a ser uma efetiva participação infantil nas cidades, as crianças subvertem as espacializações que materializam hierarquias de idade. Não é por acaso que as crianças indiscriminadamente preferem os lugares abandonados pelos adultos e se apropriam desses espaços e, a seu modo, estabelecem regras e produzem sentidos. O planejamento de espaços dirigidos à infância termina por presumir a minimização da heterogeneidade da ação entre as crianças e também entre adultos e crianças, o que insistentemente é negado pela mistura de práticas e tempos que caracteriza a cidade pelas crianças.

Mekideche (2005) fez uma pesquisa comparativa entre países europeus e países e cidades magrebinas (moradoras da região correspondente à Tunísia, Argélia e Marrocos). A pesquisadora descreve que, nos países europeus estudados, não há crianças brincando em espaços públicos, mesmo naqueles projetados para essa finalidade. Já nas cidades magrebinas, até mesmo crianças pequenas de 2 (dois) anos utilizam, para suas brincadeiras, espaços externos com identidade específica, nomeados como zankas.

Os zankas possuem uma identidade singular, não sendo nem a rua (onde há tráfego), nem a casa (onde se dá a vida privada). Trata-se de um local externo ao redor da casa do qual as crianças se apropriam e brincam uma vez que estas são consideradas como seres autônomos. Segundo a autora, a apropriação desse espaço pelas crianças reflete o fato de que, nas culturas árabes, em alguns aspectos, elas têm o mesmo poder de decisão que o adulto - decidem onde brincar.

No contexto brasileiro, por meio de oficinas, Cordeiro; Menezes e Castro (2002) analisaram as possibilidades de participação e ação da infância no espaço metropolitano de Fortaleza. Compartilhando a concepção da criança como ator social ativo também presente na reflexão da 
pesquisadora argeliana, as autoras ressaltam que as oportunidades de aprendizagem da criança não se atêm aos domínios da casa e da escola, eles são sujeitos ativos do espaço urbano.

Castro (2001b), em A Aventura urbana. Crianças e jovens no Rio de J aneiro, nas oficinas e entrevistas com crianças, observa um progressivo esvaziamento do espaço público de convivência por parte deste segmento social. Destaca também que, freqüentemente, a participação das crianças na cidade é vista de modo pouco amistoso ou negativizada como risco, uma vez que os risos, correrias e outras ações das culturas infantis perturbariam a ordenação social da urbe.

Debortoli et al. (2008), na pesquisa As experiências da infância na metrópole, trazem algumas reflexões importantes sobre a relação entre apropriação do espaço pelas crianças e posição social. O trabalho consiste em uma ampla etnografia em dois bairros de Belo Horizonte contrastantes quanto ao nível de renda dos seus moradores.

Considerando as diferenças entre os bairros mineiros, a pesquisa observa que no bairro elitizado, as crianças possuíam espaços específicos para brincar, mas não eram utilizados pelo medo da possível violência, de modo que áreas de lazer ou corredores do condomínio de luxo se convertiam em áreas apropriadas pelas crianças. Em contraponto no bairro popular, as crianças se utilizavam dos espaços públicos de convivência que, diferentes dos espaços privados, proporcionavam uma ampliação dos significados ainda que expostas à violência.

As pesquisas aqui comentadas deixam entrever que a brincadeira é um “meio de a criança viver a cultura que a cerca, tal como ela é verdadeiramente, e não como ela deveria ser" (BROUGÈRE, 2004, p. 59). A brincadeira envolve repetição, mas está longe do "como se" entendido como uma zona na qual estão suspensos os processos da vida social. Ao contrário, figura como "um fazer sempre de novo', transformação da experiência mais comovente em um hábito" (BENJ AMIN, 1985, p. 75).

Logo, brincar na cidade é uma maneira específica de se relacionar com o mundo, não sendo, portanto, uma fuga ou incapacidade de vivência de uma realidade pretensamente externa e objetiva (SARMENTO, 2008; DEBORTOLI, 2008). As brincadeiras integram culturas infantis que se definem a partir das ações cotidianas de construção de sentidos e competências sobre a vida em cidade. (SARMENTO, 2008).

\section{Método: pesquisando com crianças em uma brinquedoteca}


Dada a centralidade do lúdico na infância, as brinquedotecas constituem um universo ímpar para a pesquisa e intervenção no contexto da infância. (ANDRADE; ALTMAN, 1992; CUNHA, 1997; KISHIMOTO, 1998; RAMALHO; SILVA, 2003; KISHIMOTO; TIEMI, 2008).

A noção de brinquedoteca é polissêmica, assumindo distintas configurações que variam quanto aos objetivos, espaços, profissionais e campos disciplinares envolvidos. (NEGRINE, 1997). Em que pese a polissemia do conceito de brinquedoteca, podemos identificar um núcleo consensual que consiste na sua definição como um espaço caracterizado pela presença de jogos e brinquedos infantis que visam estimular a criação de estratégias lúdicas (MAGALHÃES, 2002).

Tendo como espaço uma brinquedoteca universitária, foram realizadas três oficinas disparadoras de brincadeiras sobre a cidade. Para tal, foi construído um pequeno cenário em dimensões compatíveis com a altura das crianças, contendo elementos característicos do município, divididos em três grupos: 1) natureza e paisagem: rio, peixes e ponte; 2) habitação/instituições: casas, escola e igreja e 3) transporte: carros, ônibus e cavalos. Dois professores participaram da atividade e duas alunas de extensão que, respectivamente, coordenaram, facilitaram e registram a experiência.

As oficinas duraram em média trinta minutos cada, sendo dividas em três fases, uma primeira introdutória, uma segunda voltada propriamente à brincadeira e uma terceira destinada ao fechamento da atividade. Para orientar o trabalho foi utilizado um roteiro dividido em etapas: abertura, desenvolvimento e fechamento. As crianças que participaram tinham entre 4 (quatro) e 9 (nove) anos, sendo todas da rede pública de ensino do município ou usuárias de creches. Assim, não houve seleção prévia das crianças que participaram da "brincadeira de cidade", todas aquelas que estavam presentes nas atividades regulares da brinquedoteca, durante os dias das oficinas, foram convidadas a participar. Cada oficina contou com a presença de uma média de 10 a 15 crianças, porém, não consistindo atividade de cunho disciplinar, nem todas, efetivamente, se envolveram na brincadeira.

Assim, um total aproximado de 45 crianças circulou na brinquedoteca durante a realização das oficinas, compondo três diferentes conjuntos de participantes. Deve-se salientar que não há registro da idade de cada criança participante das oficinas, pois não esta prática ainda não faz parte das atividades regulares da brinquedoteca na qual foi realizado o trabalho.

$\mathrm{Na}$ sessão de abertura, as crianças chegavam acompanhadas das professoras e logo se espalhavam. Para introduzir a temática, convidávamos as crianças, que o desejassem, a sentarem em círculo no 
centro do espaço, no qual fazíamos algumas perguntas sobre a cidade: Quem sabe o nome da cidade que moramos? O que vocês fazem na cidade? O que tem na cidade? Durante a fase de desenvolvimento, as crianças brincavam livremente em toda a extensão do espaço da brinquedoteca, utilizando, também, o pequeno cenário da cidade. No fechamento, compúnhamos um novo círculo e promovíamos a reflexão sobre a localização da brinquedoteca, a localização da cidade e sua apropriação, com perguntas tais como: O que vocês fizeram na cidade? Onde fica a brinquedoteca? Onde fica a universidade? Fica em Rondonópolis? O que a gente faz na universidade? Vocês conhecem outra cidade?

Cada oficina foi registrada em vídeo e em fotografia e, posteriormente, foi transcrita considerando como eixos organizadores os brinquedos/brincadeiras e como mudança de turno os movimentos da câmera ou a finalização das primeiras. Assim, a unidade de análise, portanto, foi basicamente visual. (ROSE, 2002). Nesta direção, as cenas analisadas são apresentadas com indicação da oficina e ordenação temporal, isto é, oficina e cena, não havendo indicação da idade das crianças, dada a caracterização atual do registro das crianças usuárias da brinquedoteca.

Além disso, foram realizadas notas de observação pelas pessoas responsáveis pela coordenação e facilitação das oficinas. Vale destacar que a dinâmica na brinquedoteca implica em escapar ao regime panóptico que delimita ao pesquisador o lugar de quem tudo vê, pois dada a multiplicidade espacial e de práticas, não há a possibilidade de um olhar totalizador acerca das atividades.

\section{Discussão dos resultados}

\subsection{Relações entre crianças, cidade e brinquedoteca}

Os principais temas/brincadeiras relacionados à apropriação do urbano emergentes nas oficinas não se restringiram aos elementos disponíveis no pequeno cenário característicos do município onde vivem. Aliás, em algumas situações, o cenário foi desmontado e seus elementos ganharam novos sentidos. Cena emblemática pode ser encontrada no episódio no qual uma criança "pesca" a igreja do pequeno cenário, correndo com a mesma pela sala.

Meninos sobre a ponte pescando. Uma das crianças "pesca" a igreja que está logo à frente. Meninas do carro rosa passam sobre a ponte. (...) Uma das crianças passa em frente a câmera exibindo seu peixe (a igreja), e diz para os seus colegas: "olha o meu peixe! Peguei o peixe! Peguei o Peixe! Aqui ó, peguei o peixe! Ninguém dá atenção ao "peixe" de Joaquim e ele retorna 
para a ponte com a igreja (não mais o peixe) e tenta recolocá-la com a vara de pescar (Oficina 1, Cena 10).

$\mathrm{Na}$ análise das cenas, três aspectos chamaram a atenção: (1) a pluralidade de sentidos do termo cidade no contexto das falas e práticas, (2) a relação entre adultos e crianças durante as oficinas e (3) a relação entre brinquedoteca e universidade.

\subsection{Cidade, uma palavra, múltiplos sentidos}

Nas oficinas se destaca a circulação de diversos sentidos da palavra cidade, de maneira que o município parece abarcar várias outros espaços: a cidade do centro, a cidade do bairro distante ou, ainda, aquela diferente da universidade que estaria no seu exterior. Nas distintas acepções, a organização do espaço é atravessada pelas diferenças sociais que delimitam dinâmicas de circulação no espaço urbano.

Para fins deste trabalho, entendemos bairro como "pedaço de cidade atravessado por um limite distinguindo o espaço privado do público", ou seja, um espaço entre o público e o privado que se distingue de ambos, sem que, contudo, com eles se confunda inteiramente (MAYOL, 1999). Em uma das situações, a "cidade" é apresentada como sendo o centro, ou mais propriamente, o comércio, o espaço de lazer diferente do bairro onde vivem. Assim, vai-se à cidade, saindo-se do local de moradia.

Monitora: Esse ônibus ta indo para onde?/A criança aponta para frente e diz: Para cidade.../Monitora: Pra cidade.../Criança: De Rondonópolis.

Monitora: De Rondonópolis. O que vai fazer na cidade?/Criança: Eu?

Monitora: É./Criança: Vou passear. (Oficina 2, Cena 3)

Em outra situação, o bairro Jardim Tropical, situado na periferia, é apresentado como outra cidade, distinta daquela aonde as crianças se encontram no momento da brincadeira:

\footnotetext{
Monitora: Qual outra cidade que vocês foram?/Criança responde: Eu já

Monitora: Qual cidade que você foi?/Criança: Pro Tropical/Monitora: O Tropical fica longe?/A criança balança a cabeça afirmativamente. (Oficina 3, Cena 6)
}

Na abertura de uma das oficinas, uma criança quando argüida sobre onde ficava o município aonde mora, reponde que "lá do outro lado", ou 
seja, longe da universidade que, por sua vez, estaria fora do contexto citadino.

Monitora: Qual o nome dessa cidade?/As crianças respondem em coro: - Rondonópolis!/Pesquisador: $E$ onde é que fica Rondonópolis?/Criança: Lá do outro lado da cidade (Oficina 1, Cena 5)

A casa onde moram foi trazida como um espaço de conserto e de construção, realidade vivida pela maior parte dessas crianças que vivem em habitações semi-construídas e convivem com o desejo dos pais de terminarem essa tarefa. O trabalho é a ação efetuada nesse e em outros espaços. A forma como a rotina laboral é expressa, a partir da repetição e da concentração com que empreendem a tarefa, indica a importância dessa ação na vida na cidade.

Uma criança conduz o seu carro até a casa./A monitora observa
e diz: Vai estacionar o carro?/Uma criança fala pela janela da
casa: Tio. Ó tia, nós tamo trabalhando./Monitora: Estão
trabalhando? Na cidade trabalha?/A criança não responde e com
o seu martelo bate nas paredes.
Monitora: Oi? Posso trabalhar o seu serviço?/A criança faz um
gesto de não com a cabeça./Outra criança aparece dentro da
casa.
Criança: Pode./Monitora: E o que vocês são?/Criança: É o
trabalhador. (Oficina 2, Cena 4)

No âmbito da cidade como lugar de circulação, as crianças trazem, talvez, o que há de mais urbano: o trânsito, com destaque, para os acidentes, buzinas e o uso do transporte coletivo. As crianças apropriam-se da rotina urbana, das suas estratégias de deslocamento nas quais ficam claras as dinâmicas de segregação materializadas no espaço que atravessam grande parte das brincadeiras.

Aspectos menos urbanos, relacionados à paisagem natural, também aparecem, marcando a presença de práticas que destoam do ritmo citadino tais como o trânsito e seus acidentes. Assim, as crianças pescam como forma de lazer na cidade ou ainda, andam a cavalo. Incorporam o próprio ritmo de urbanização do município de médio porte situado em Mato Grosso.

\subsection{Relações entre adultos e crianças na brinquedoteca}

$\mathrm{Na}$ brinquedoteca, os adultos (professores, educadores e monitoras) ocupam uma posição secundária, sendo o ritmo das atividades marcado pelas crianças, o que levou alguns docentes envolvidos nas atividades, aqui lócus de pesquisa, à afirmação de um pretenso "fracasso" de 
algumas oficinas dada a "agitação" e "indisciplina" das crianças. Como indicam reflexões anteriores, o pesquisar com crianças envolve sempre uma abertura ao imprevisível dado que os roteiros das oficinas são, freqüentemente, modificados e apropriados pelas crianças (DELGADO; MÜLLER, 2005).

Em várias situações, as monitoras envolvidas na atividade tentaram obter "explicações" sobre as atividades em curso ou entrar nas brincadeiras, sendo em diversos episódios, respondidos de modo lacônico ou mesmo colocados em situação de invisibilidade. Veja-se transcrição de uma destas cenas nas quais a pesquisadora busca entrar na brincadeira:

Uma criança está dentro da casa vermelha com a porta fechada. A pesquisadora bate na porta e vocaliza: "toc.toc. Abre a porta". /Abre a porta e pergunta: "Está em casa? Está fazendo o que em casa?"/Criança meneia a cabeça./Monitora: Você está brincando?/Novamente a criança balança a cabeça./Monitora: Você não gosta de carro?/A criança não responde./Monitora: quer brincar aqui fora?/A criança balança a cabeça negativamente./A monitora se levanta e deixa a criança (Oficina 2, Cena 8).

O suposto silêncio ou as falas mínimas das crianças, assim como a "agitação" e "indisciplina", nem sempre são bem recebidos pelos adultos que as bombardeiam com perguntas-teste para as quais já tem uma resposta (CORSARO, 2005). Aparentemente faz-se visível o desejo de "entrar na cabeça" das crianças, saber o que estariam pensando, fugir ao aparentemente jogo incompreensível da agitação ou do silêncio. Busca-se o "dentro" da criança, esquecendo-se o que ocorre "entre" as mesmas (DELGADO; MÜLLER, 2005).

Durante as oficinas, as perguntas-teste, freqüentemente, conduziram ao fracasso das tentativas de diálogo entre pesquisadores e crianças. Veja-se exemplo:

A monitora indaga a uma criança que brinca com um colega e está sentada na frente do carro de papelão: "Vocês estão indo para onde?"

Crianças: "Não sei"/Monitora: "Não sabe. Tem que ter uma direção."

As duas crianças empurram o carrinho em direção oposta, um deles acena "tchau" com a mão enquanto a outra está com a varinha de pescar e lança em direção ao rio (Oficina 3, Cena 9).

Punch (2002) nos lembra de que o modo pelo qual pesquisadores percebem a infância e o status da criança na sociedade atua no modo 
como estes são compreendidos no contexto das produções acadêmicas. A partir desta assertiva, compreendemos que a reação à "agitação" e "indisciplina" das crianças diz da presença de um repertório discursivo que liga as mesmas à ausência de ordem, o que na cidade, conduz ao delineamento de espaços destinados apenas a sua presença, ou ainda, a sua exclusão de outros espaços.

Em síntese, os modos de ver a criança influenciam o modo com as escutamos, nos métodos de coleta e análise que selecionamos. Nas oficinas, a "agitação" e "indisciplina" das crianças apareceram na transcrição da finalização da terceira oficina, sendo descrita como o incidente que conduz à finalização: "O barulho se intensifica e as crianças se dispersam, as pesquisadoras encerram as oficinas" (Oficina 3, Cena 15).

$\mathrm{Na}$ descrição do encerramento da oficina, visivelmente, as monitoras esperavam que as crianças cumprissem um protocolo pré-determinado ou, minimamente, houvessem se comportado como um adulto se comportaria, não havendo, portanto, uma diferenciação entre as culturas adultas e infantis. Este tem sido um desafio não apenas para as oficinas aqui analisadas, mas comum a outras práticas realizadas nesse contexto educativo (LEMOS-DE-SOUZA; GALINDO, 2008).

\subsection{Relações entre brinquedoteca e universidade}

Em seu diário de campo, a coordenadora da brinquedoteca anota uma interessante observação na qual relata que uma criança, pela primeira vez na brinquedoteca, quando perguntada sobre onde estava, respondeu: "em São Paulo capital". Quando indagada sobre os motivos de tal afirmação, justificou que o lugar era muito bonito. Forma de apropriação do espaço que desloca a brinquedoteca da sua inscrição geográfica, sendo atravessadas pelas imagens que a criança tem do que vem a ser uma capital, sejam elas provenientes de viagens, conversas ou de narrativas midiáticas (SALGADO; JOBIM; SOUZA, 2007).

A apropriação do espaço da universidade (suposto universo exclusivo do adulto) pelas crianças vem conduzindo a críticas no interior da instituição na qual se localiza a brinquedoteca, sendo solicitada a remoção deste espaço para um lugar afastado, pois as crianças perturbariam o ambiente universitário. Na universidade onde foi realizada a pesquisa, dificilmente, encontramos espaços intermediários passíveis de ocupação infantil tais como os zanka estudados por Mekideche (2005), pois entrar e sair da universidade supõe atravessar os controles de acesso das portarias.

Corsaro (2005), em revisão de diferentes experiências etnográficas com crianças empreendidas por adultos, observa que uma das questões 
axiais pode ser sintetizada na indagação "O que há de fazer um homem crescido para ser aceito nos universos das crianças?". Nas brinquedotecas universitárias, talvez, se possa elencar uma nova pergunta: "O que hão de fazer as crianças para serem aceitas na universidade?", ou ainda, "Como podemos fazer com que essas brinquedotecas sejam diferentes dos espaços para crianças e sua lógica de ordenação?".

O conflito provocado pelo ingresso das crianças na brinquedoteca universitária se materializou em uma reforma no seu espaço. Foi criada uma porta externa ao edifício no qual são realizadas as aulas, por meio da qual devem entrar as crianças sem que estas passem pelos corredores da universidade. Atravessamento da ordenação urbana que não se restringe às cidades (BERTUOL, 2008), mas perpassa o espaço universitário, assumindo aí uma lógica distinta caracterizada pelo esforço constante de manutenção da ordem necessária à aprendizagem do corpo de aprendizes do qual estão excluídas as crianças.

Nas reflexões finais de uma das oficinas, ao serem indagadas sobre a relação entre universidade, brinquedoteca e cidade, uma das crianças afirmou que a universidade estava dentro da brinquedoteca, nomeandoa como Universidade da brinquedoteca.

Pesquisador pergunta a algumas crianças: "Como chama esse local?"/Uma criança responde: "brinquedoteca, brinquedoteca da universidade"./Pesquisador continua: "e qual é a universidade?"/Criança: "universidade da brinquedoteca" (Oficina 1, Cena 15).

\section{Considerações finais}

No contexto de pesquisa, na qual foi disponibilizado um pequeno cenário com elementos que faziam referências à cidade, a circulação uniu os lugares do contexto urbano. Assim, circular foi a palavra de ordem na cidade, onde a rotina e o cotidiano racionalizam a vida pública e privada. Viver a cidade é circular, transitar em seus diferentes espaços, usufruir de suas distintas funções e é, também, evitar determinados espaços.

O cenário foi tão somente um disparador de brincadeiras, pois as crianças subverteram os lugares, objetos e funções, fazendo uso dos demais recursos lúdicos disponíveis na brinquedoteca. Na brincadeira os objetos, lugares a qualquer momento mudavam de função e forma.

As pequenas subversões mostram-nos a cidade como um espaço e um lugar onde se está, composta por diferentes nichos, que podem ser visitados, utilizados, modificados ou, ainda, posicionados como inacessíveis, não devendo ser visitados. Mas, se abertura à subversão e modificação de dinâmicas se faz presente, também chama atenção as 
insistentes dificuldades de acesso a alguns espaços públicos. A circulação limitada à periferia da vida citadina torna alguns espaços inviáveis de serem ocupados, seja porque se situam longe geograficamente, seja porque, mesmo próximos são posicionados como inacessíveis.

As crianças trouxeram, também, a sua condição de vida e suas relações com diversos espaços, tais como a casa, a escola, a igreja e o trabalho. O trabalho apareceu como referência que atravessa a vida da criança e a dinâmica da cidade. Trabalha-se na casa onde se mora; entra-se no ônibus, coloca-se o capacete para ir ao "serviço".

Vimos também que, na brinquedoteca, as interações entre adultos e crianças atualizaram a dificuldade de tomar as crianças de modo ativo, sendo atualizadas distintas assimetrias. Pesquisadores e monitoras, em várias situações, demandaram a ordenação da brinquedoteca recorrendo à racionalidade da inclusão planejada que se faz presente,em escala ampliada, na cidade.

Para escapar à racionalidade da inclusão planejada é necessária uma participação ativa das crianças no cotidiano da brinquedoteca. Mas, como mostram as oficinas, ainda é difícil saber como incluí-las sem cair no risco da assimetria com base em hierarquias de idade e na ausência de crítica que conduz à utilização do espaço como mera ocupação do tempo. Em parte, essa dificuldade marca a própria história deste lugar institucional. Brinquedotecas participam da mesma lógica que preside à formação de lugares para crianças (BERTUOL, 2008). Transita entre a ocupação do tempo livre, a oferta de bens simbólicos e a proposição de ativa de um espaço crítico e reflexivo.

Com a criação da brinquedoteca, a Universidade, inicialmente, um espaço fora das rotinas de circulação das crianças, passa a ser apropriada pelas mesmas como um lugar possível - um lugar para "brincar". Para as crianças, a universidade "cabe" na brinquedoteca. Em contraponto, para os adultos e jovens - professores e alunos - a brinquedoteca parece não "caber" na universidade. Delineia-se uma zona de dificuldades de diálogo entre gerações.

Trazer as crianças para a universidade, por si só é um grande mérito, pois, como vimos, implica em romper uma dinâmica de segregação espacial. Permanece, entretanto, como desafio a promoção do diálogo entre adultos e crianças de modo que ambos "caibam" na possibilidade de um esforço conjunto de crítica à segregação da circulação das crianças em alguns espaços considerados não infantis, como, por exemplo, a universidade.

As oficinas parecem sugerir que o diálogo entre gerações, apoiado numa constante reflexão sobre as assimetrias etárias colocadas em 
funcionamento, pode ser uma via importante para que a brinquedoteca funcione como espaço para crítica à racionalidade que permitiu sua emergência, indo além de um espaço para crianças. Caminho aberto a novas investigações e práticas de intervenção.

\section{Referências Bibliográficas}

ANDRADE, C. M. R. J.; ALTMAN, R. Z. As brinquedotecas brasileiras. In: FRIEDMANN, A. (Org.). O direito de brincar: a brinquedoteca. São Paulo: Scritta, p. 234-260, 1992.

ARIÉS, P. História da criança e da família. Rio de Janeiro: Guanabara, 1981.

BENJAMIN, W. Reflexões: a criança, o brinquedo e a educação. São Paulo: Summus Editora, 1985.

BERTUOL, C. Crianças no espaço urbano: um estudo sobre políticas públicas no contexto das "Cidades Amigas das Crianças". 160f. Tese (Doutorado em Psicologia Social) - Programa de Estudos Pós-Graduados em Psicologia Social. Pontifícia Universidade Católica de São Paulo. São Paulo, 2008.

BROUGĖRE, G. Brinquedo e Companhia. São Paulo: Cortez, 2004.

CASTRO, L. R. Cities and Social Participation: Social Inequalities from Children's and Youth's Points of View. International Journal of Anthropology, Nova York, v. 16, n. 2-3, p. 77-87, 2001 la.

A Aventura urbana. Crianças e jovens no Rio de Janeiro. Rio de Janeiro: Nau/FAPERJ, 2001b.

Conhecer, transformar(-se) e aprender: pesquisando com crianças e jovens. In: BESSET, V. L.; CASTRO, L. R. (Org.). Pesquisa-intervenção na infância e na juventude. Rio de Janeiro: Trarepa/FAPERJ, p. 21-42, 2008. CORDEIRO, A. C. de F.; MENEZES, J. de A.; CASTRO, L. R. de. Oficinas da cidade em Fortaleza. Psicologia: Reflexão e Crítica, Porto Alegre, v. 15, n. 1, p. 53-61, 2002.

CORRÊA, M. A cidade de menores: uma utopia dos anos 30. In: FREITAS, M. C. (Org.). História Social da Infância no Brasil. São Paulo: Cortez, p. 81-99, 2006.

CORSARO, W. A. Entrada no campo, aceitação e natureza da participação nos Estudos etnográficos com crianças pequenas. Educação \& Sociedade, Campinas, v. 26, n. 91, p. 443-464, maio/ago. 2005.

CRUZ, S. G. F. P. Quando a condição de existência condena e os estilos de vida se tornam perigosos. In: JUSTO, J. J.; CARDOSO JUNIOR, H. R.; FRANÇA, S.; ROCHA, L. C.; CRUZ, S. P. Estratégias de controle social: errânciacriminalização-gestão de risco. São Paulo: Arte e Ciência/Unesp, 2004, p. 6999.

CUNHA, N. H. da S. A brinquedoteca brasileira. In: SANTOS, S. M. P. dos (Org.). Brinquedoteca: o lúdico em diferentes contextos. 4 ed. Petrópolis: Vozes, p. 13-22, 1997.

DEBORTOLI, J. A. O. Imagens contraditórias da infância: crianças e adultos na construção de uma cultura pública e coletiva. In: DEBORTOLI, J. A. O.; 
MARTINS, M. de F. A.; MARTINS, S. (Org.). I nfâncias na metrópole. Belo Horizonte: Editora UFMG, p. 71-80, 2008.

DEBORTOLI, J. A. O.; MARTINS, M. F.; MARTINS, S.; PIMENTA, J. ; BARBOSA, R. S.; SENRA, E. B. As experiências de infância na metrópole. In: DEBORTOLI, J. A. O.; MARTINS, M. de F. A.; MARTINS, S. (Org.). Infâncias na metrópole. Belo Horizonte: Editora UFMG, p. 19-46, 2008.

DELGADO, A. C. C.; MÜLLER, F. Apresentação: "Sociologia da infância: pesquisa com crianças". Educação e Sociedade, Campinas, v. 26, n. 91, p. 351-360, maio/ago. 2005.

FUNDABRINQ. Guia prefeito amigo da criança: propostas de políticas e ações para as gestões municipais 2001-2004. São Paulo: FADC, 2001. Disponível em: <www.fundabrinq.org.br>. Acesso em: 27 abr. 2009.

GOMES, A. M. R.; GOUVÊA, M. C. S. de. A criança e a cidade: entre a sedução e o perigo. In: DEBORTLI, J. A. O.; MARTINS, M. de F. A.; MARTINS, S. (Org.). I nfâncias na metrópole. Belo Horizonte: Editora UFMG, p. 47-70, 2008.

GOVERNO DO ESTADO DE SÃO PAULO. Estatuto da Criança e do Adolescente. São Paulo: IMESP, 1990.

SOUZA, S. Re-significando a psicologia do desenvolvimento: uma contribuição crítica à pesquisa da infância. In: KRAMER, S.; LEITE, M. I. Infância: fios e desafios da pesquisa. Campinas: Papirus, p. 39-56, 1997.

KISHIMOTO, T. M. Diferentes tipos de brinquedoteca. In: FRIEDMANN, A. 0 direito de brincar: a Brinquedoteca. 4. ed. São Paulo: Abrinq, p. 53-63, 1998.

KISHIMOTO, T. M.; TIEMI, A. O. Brinquedo, gênero e educação na brinquedoteca. Pro-posições. Campinas, v. 19, n. 3, p. 209-223, 2008.

LEMOS-DE-SOUZA, L.; GALINDO, D. C. G. Ética e diversidade na formação de educadores. In: ROCHA, S. A. da. (Org.). Formação de professores e práticas em discussão. Cuiabá: EdUFMT, p. 203-219, 2008.

LEMOS, F. C. S. A apropriação do brincar como instrumento de disciplina e controle das crianças. Estudos e Pesquisas em Psicologia, Rio de Janeiro, v. 7, n. 1, p. 78-88, 2007.

A Educação como dispositivo de proteção às crianças e adolescentes segundo práticas do UNICEF: problematizações foucaultianas, Estudos e Pesquisas em Psicologia, Rio de Janeiro, v. 8, n. 3, p. 559-577, 2008.

LYNCH, K. Growing Up in Cities. Cambridge: The Mit Press, 1977.

MAGALHAES, C. M. C.; PONTES, F. A. R. Criação e manutenção de brinquedotecas: reflexões acerca do desenvolvimento de parcerias. Psicologia Reflexão Crítica, Porto Alegre, v. 15, n. 1, p. 235-242, 2002.

MARCílLIO, M. L. A roda dos expostos e a criança abandonada na História do Brasil. 1726-1950. In: FREITAS, M. C. História Social da I nfância no Brasil. São Paulo: Cortez, p. 53-82, 2006.

MAYOL, P. Morar. In: CERTEAU, M. de. A invenção do cotidiano: 1 . Artes de fazer. Petrópolis: Vozes, 1999, p. 37-166.

MEKIDECHE, T. Zanka: Apropriação do Espaço Urbano Pelas Crianças das Cidades Magrebinas. Psicologia USP, v. 16, n. 1/2, p. 115-118, 2005. 
MÜLLER, F. Infâncias nas vozes das crianças: culturas infantis, trabalho e resistência. Educação e Sociedade, Campinas, v. 27, n. 95, p. 553-573, 2006.

NEGRINE, A. Brinquedoteca: teoria e prática. In: SANTOS, S. M. P. dos. (Org.). Brinquedoteca: o lúdico em diferentes contextos. 4 ed., Petrópolis: Vozes, 1997, p. 83-94.

PUNCH, S. Research with children: the same or different from research with adults? Childhood, v. 9, n. 3, p. 321-341, 2002.

RAMALHO, M. R. de B.; SILVA, C. C. M. da. A brinquedoteca. In: Revista ACB: Biblioteconomia em Santa Catarina, Florianópolis, v. 8, n. 1, p. 26-34, 2003.

ROSE, D. Análise das imagens em movimento. In: BAUER, M.; GASKELL, G. (Org.). Pesquisa qualitativa com texto, imagem e som: um manual prático. Petrópolis: Vozes, 2002, p. 343-365.

SALGADO, R. G.; SOUZA, S. As Crianças na Rede da Cultura Lúdica Contemporânea. In: COSTA, M. de F. V.; COLAÇO, V. de F. R.; COSTA, N. B. da. (Org.). Modos de brincar, lembrar e dizer: discursividade e subjetivação. Fortaleza: Edições UFC, 2007, p. 21-39.

SARMENTO, M. Sociologia da infância: correntes e confluências. Educação e Sociedade, v. 26, n. 91, p. 361-378, maio/ago. 2005.

$\overline{2} \overline{0} \overline{0}$.

Estudos da infância: educação e práticas sociais. Petrópolis: Vozes,

UNICEF. The child friendly cities project. Florence, 1996. Disponível em:

<www.childfrindlycities.org>. Acesso em: 15 ago. 2009.

\section{Endereço para correspondência}

Dolores Galindo

Mestrado em Estudos da Cultura Contemporânea - ECCO/UFMT, Universidade Federal de Mato Grosso - UFMT, Instituto de Linguagens / ECCO, Av. Fernando Corrêa da Costa, no 2367, sala 44/IL, Bairro Boa Esperança, CEP 78060-900, Cuiabá - MT, Brasil

Endereço eletrônico: doloresgalindo@ufmt.br

Leonardo Lemos de Souza

Universidade Federal de Mato Grosso, Curso de Psicologia, Campus Universitário de Rondonópolis - UFMT, Rodovia Rondonópolis-Guiratinga MT 270, km 06, CEP 78735910, Áreas Internas, Rondonópolis, MT, Brasil

Endereço eletrônico: llsouza@hotmail.com

Morgana Moura

Universidade Federal de Mato Grosso, Curso de Psicologia, Campus Universitário de Rondonópolis - UFMT, Rodovia Rondonópolis-Guiratinga MT 270, km 06, CEP 78735910, Áreas Internas, Rondonópolis, MT, Brasil

Endereço eletrônico: morganamanon@hotmail.com

Vanusa Rodrigues

Universidade Federal de Mato Grosso, Curso de Psicologia, Campus Universitário de Rondonópolis - UFMT, Rodovia Rondonópolis-Guiratinga MT 270, km 06, CEP 78735910, Áreas Internas, Rondonópolis, MT, Brasil

Endereço eletrônico: br.vanusa@gmail.com

Recebido em: 26/08/2009 
Aceito para publicação em: 22/03/2010

Acompanhamento do processo editorial: Deise Mancebo

\section{Notas}

* Doutora em Psicologia Social - PUC-SP; Docente do Mestrado em Estudos da Cultura Contemporânea e do Curso de Psicologia da Universidade Federal do Mato Grosso UFMT, Cuiabá, MT, Brasil

**Doutor em Educação - UNICAMP, Docente do Mestrado em Educação e do Curso de Psicologia da Universidade Federal de Mato Grosso- UFMT, campus Rondonópolis, MT, Brasil

***Bolsista de Iniciação Científica - PIBIC/CNPq 